\title{
A produção científica brasileira sobre estudos bibliográficos: uma análise diacrônica
}

\author{
Leilah Santiago Bufrem \\ Doutora; Universidade Federal da Paraíba, João Pessoa, PB, Brasil; \\ santiagobufrem@gmail.com
}

\begin{abstract}
Resumo: Descreve as concepções teóricas e as atividades concretas relacionadas ao domínio da Bibliografia no Brasil, considerando seu desenvolvimento teórico e aplicado, a partir da produção científica em artigos de periódicos indexados na Brapci. A pesquisa objetiva identificar a produção sobre o tema bibliografia, por meio de busca e análise da literatura científica indexada na Brapci; delinear o perfil dessa produção, privilegiando as categorias pesquisadores, temas e influências teóricas da área de CI e contextualizar as concepções e atividades na conjuntura em que se destacaram. Analisa diacronicamente a produção sobre o tema, para evidenciar a evolução do conceito de bibliografia presente na produção científica no Brasil, destacando as concepções e atividades a ele pertinentes. É um estudo de caráter diacrônico e descritivo, que se volta ao conteúdo dos artigos, a partir de categorias de análise e informações levantadas na produção científica considerada, correspondente ao período entre 1972 e 2017. Observa que, na literatura produzida no Brasil sobre o tema bibliografia, a ênfase apresenta-se na dimensão tecno metodológica, concretizada no fazer biblioteconômico e documentário, explicitando e organizando ferramentas de trabalho e estudo, seguindo-se a dimensão sociopolítica, relacionada com as intervenções em formas variadas na produção de instrumentos de apoio ao conhecimento e sua concretização em prol dos interesses abrangidos pelas políticas sociais e, com menor expressividade, no conjunto da produção, apresenta a dimensão teórico epistemológica, relacionada aos fundamentos e reconstrução racional e histórica da arte da bibliografia e da ciência bibliográfica.
\end{abstract}

Palavras-chave: Bibliografia. Produção científica. Bibliografia no Brasil. Estudos bibliográficos.

\section{Introdução}

O mote para este estudo, encontrado no artigo fundante de Shera, Toward a Theory of Librarianship and Information Science (1973), focaliza a bibliografia, por ele compreendida como toda atividade que pretende colocar usuário e livro juntos. Consoante a sua ideia de que a biblioteconomia é "fundamentalmente 
ciência do comportamento", pode-se concordar com sua afirmação de que, enquanto ciência, ela "constrói tão bem quanto destrói”. Desse modo, o autor argumenta que a década de 1970 deveria ser mais dedicada às ciências sociais do que às ciências físicas e essa proposta pode ser oriunda da ênfase dada à máquina pelos recursos tecnológicos aplicados à informação, de modo especial em detrimento dos aspectos humano, lógico e linguístico. Considerando-se essa preocupação, parte-se do pressuposto de que o conceito de bibliografia, presente na produção científica em periódicos no Brasil, pode ser analisado em sua evolução, evidenciando-se concepções e atividades a ele relacionadas e considerando-se o contexto em que ocorrem.

O termo Bibliografia, etimologicamente significando a descrição de livros, "carrega sua tocha de investigação em todas as partes do conhecimento", declara Mouravit. Ao atribuir o mérito da bibliografia ao mundo do ensino e o problema bibliográfico como o central para os bibliotecários, o autor inspira-se numa visão da biblioteca como a grande agência da educação universal. Essa visão aproxima-se de uma dimensão teórico epistemológica, cuja prioridade é a compreensão das formas de conhecimento e os modos de realizá-lo, como se pode depreender também da acepção de Malclès, que define a bibliografia como:

[...] o conhecimento de todos os textos impressos ou multigrafados. Fundamenta-se na pesquisa, na identificação, descrição e classificação de documentos, a fim de organizar serviços ou construir instrumentos destinados a facilitar o trabalho intelectual (apud BRIET, 1951, p.8).

Mas permite, também, que se admita a bibliografia como uma construção orgânica e viva, cuja exposição para o mundo se insere nos momentos históricos em que os processos formativos possam ser orientados pelos sentidos da vida social, das escolhas possíveis, na própria vida social em sua complexidade, em prol da compreensão e da atuação no campo em que se situa. Segundo concepção de Edson Nery da Fonseca (1979): as primeiras bibliografias surgem "no recesso de grandes bibliotecas, particulares ou públicas. Quem possui ou dirige uma coleção, sente-se naturalmente inclinado a descrevê-la e não apenas a conservá-la e enriquecê-la".

Em Questão, Porto Alegre, v. 25, p. 67-88, Edição Especial V Seminário Internacional A Arte da Bibliografia, 2019 doi: http://dx.doi.org/10.19132/1808-5245250.67-88 
Reconhecendo-se o termo bibliografia como de largo uso, não somente entre os amantes e profissionais do livro, quanto entre agentes de campos distintos do conhecimento e da atuação profissional, para expressar o conjunto de obras ou itens utilizados como apoio do estudo realizado ou por realizar, a bibliografia e sua história no Brasil são parte do objeto construído para se mostrar nesta breve comunicação. Em outras palavras, quando se retoma a história conceitual deste termo, percebe-se que, se hoje ele representa um amplo espectro de atividades relacionadas ao livro, ele tem sido historicamente objeto de discussões sobre modos de compreender os sentidos e os resultados de sua utilização concreta.

Assim, ao delinear o perfil biobibliográfico do cientista, erudito e bibliógrafo suíço Conrad Gessner (1516-1565), dando destaque ao seu pioneirismo bibliográfico, Araujo (2015) identifica, de forma sumária, aspectos bibliográficos da obra Bibliotheca Universalis, além de analisar as interfaces da Bibliografia, em particular a bibliotecária e material, para recuperar elementos constitutivos da cultura bibliográfica, do ponto de vista descritivo e semântico e discutir seu sentido como dispositivo de mediação e memória.

A bibliografia, atividade central do bibliotecário, desconsiderando a especialização de assunto e estimulada pela tecnologia da comunicação, teoria geral dos sistemas, automação e tecnologias correlatas, estaria se afastando das humanidades (SHERA, 1972). A tese subjacente à afirmação de Shera, de que os sistemas bibliográficos e de informação devem ser estruturados segundo padrões humanos e suas formas de produção do conhecimento, tem perpassado a literatura científica no Brasil, desde as primeiras produções sobre o tema, ainda na década de 1970, quando o autor escreveu este artigo fundante.

A crítica incisiva de Edson Nery da Fonseca (1973) a autores ingleses que, por autossuficiência ou ignorância de línguas neolatinas, omitem nomes de pioneiros de outros países, em estados da arte sobre os temas tratados, é ilustrada com o exemplo de Bradford que, historiando "Cinqüenta anos de documentação", deixou de mencionar brasileiros cujas contribuições para a consolidação do Instituto Internacional de Bibliografia foram decisivas. Essa contribuição teria ocorrido na fase heroica em que esse órgão, em 1938, 
transformado na Federação Internacional de Documentação, sofreu oposições na própria Europa. Entretanto, quatro anos depois de fundado, em Bruxelas, o Instituto Internacional de Bibliografia já contava, entre seus membros, com o sábio brasileiro Juliano Moreira, conforme registro no opúsculo do engenheiro paulista Victor Alves da Silva Freire, intitulado "A bibliographia universal e a classificação decimal”, segundo registro de Edson Nery da Fonseca (1973).

Essa constatação sobre a extensão temporal possível para a compreensão do objeto deste estudo levou-nos a delimitar a problemática deste trabalho, questionando sobre as características dominantes na literatura relacionada aos estudos bibliográficos no Brasil aqui analisada, para que se possam identificar as concepções e manifestações mais expressivas e as tendências que a distinguem.

Procurou-se, com esta pesquisa, descrever as concepções e atividades concretas relacionadas ao conceito de bibliografia, a partir da produção científica em artigos de periódicos indexados na Base de Dados em Ciência da Informação (Brapci).

Especificamente, buscou-se estudar a produção sobre o tema bibliografia, por meio da identificação e análise da literatura científica indexada na Brapci; delineando o perfil dessa produção científica e contextualizando as concepções e atividades na conjuntura em que se destacam e nas dimensões que as conformam.

Aqui considerada um símbolo de resistência e convicção de praticamente uma vida a ela dedicada, valem os parênteses para informar que a Brapci (2010) se concretizou a partir de um trabalho de reconhecimento, iniciado quando da concepção do nosso projeto de pós-doutorado (BUFREM, 1995), como primeiro passo com vistas à construção de um repertório representativo da produção científica dos países envolvidos, Brasil e Espanha e por isso sua denominação original de base Bres ${ }^{1}$. O propósito inicial dessa concepção era proporcionar ambiente tecnológico e operacional para a realização de estudos comparativos, como já vinham sendo realizados com dificuldades, devido à falta de padronização e de repositórios específicos da área, uma vez que nem todos os periódicos eram indexados nas bases de dados e que essas em geral são bases referenciais ${ }^{2}$.

Em Questão, Porto Alegre, v. 25, p. 67-88, Edição Especial V Seminário Internacional A Arte da Bibliografia, 2019 doi: http://dx.doi.org/10.19132/1808-5245250.67-88 


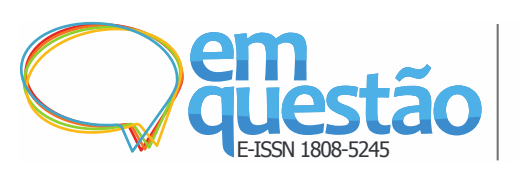

A produção cietífica brasileira sobre estudos bibliográficos: uma análise diacrônica Leilah Santiago Bufrem

O recorte deste estudo privilegia o tipo de literatura científica periódica por se tratar de um objeto de estudo valorizado, em determinado contexto social e momento histórico, portanto, capaz de refletir as mudanças e contradições desse contexto, tanto em relação ao seu conteúdo, quanto a sua organização interna e suas aplicações. Além disso, a produção científica, seja qual for o seu grau de desenvolvimento ou a sua opção metodológica, pressupõe a ação intencional do pesquisador consciente das suas condições e limitações de produção, que incorpora concepções e seleciona procedimentos em situações estruturais concretas que dão sentido e significado a sua práxis.

Realizar uma pesquisa mais ampla, sobre elementos constitutivos da cultura bibliográfica no Brasil, exigiria um esforço desproporcional ao tempo e espaço oferecidos como limitação para um artigo, impondo-se o recorte, pautado em razão de ordem prática: a existência da base Brapci, como registro da produção periódica do período que cobre.

Gráfico 1 - Quantidade anual de trabalhos sobre Bibliografia identificadas na base Brapci.

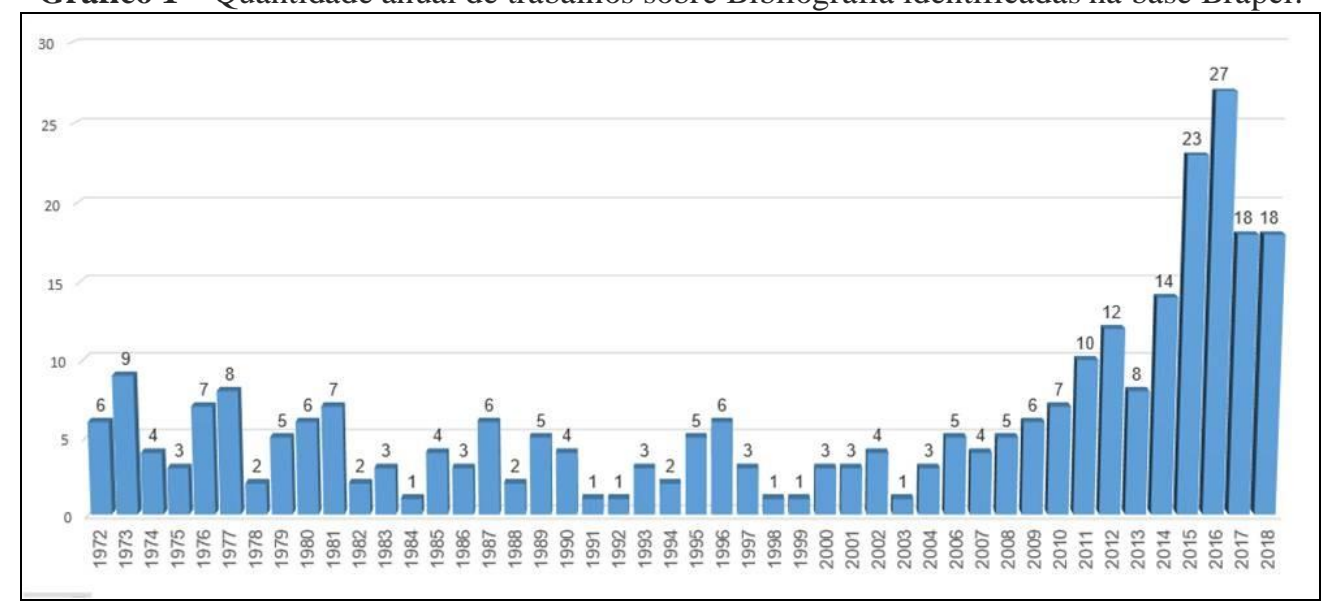

Fonte: Dados da pesquisa (2018).

Assim, ao caracterizar essa produção mostram-se as ênfases nela presentes, consideradas as dimensões escolhidas. A produção recuperada pela Brapci, extrapolando esses limites, oferece depoimentos e registros inesperados, tais como ilustra bem o texto de Paulo Terra Caldeira (1983), remetendo ao movimento editorial no Primeiro Reinado como uma indústria florescente, quando os intelectuais e escritores deixam de enviar seus originais para publicação em Lisboa e em outros países europeus, para editá-los aqui. No Em Questão, Porto Alegre, v. 25, p. 67-88, Edição Especial V Seminário Internacional A Arte da Bibliografia, 2019 
artigo "Bibliógrafos brasileiros: levantamento preliminar", ele discute a importância das compilações bibliográficas iniciadas no Brasil em 1835 com a lista de Obras de medicina publicadas no Rio de Janeiro no decurso de 1834, identificando 53 autores brasileiros que compilaram quatro ou mais bibliografias utilizando-se, para isto, das bibliografias brasileiras de Antônio Simões dos Reis e de Bruno Basseches. Destaca-se, para ilustrar, que, embora em 1808, tenha se iniciado a impressão dos primeiros livros no país, os repertórios que registram obras de autores estrangeiros que escreveram sobre o Brasil apontam trabalhos publicados desde 1504 (CALDEIRA, 1983).

A percepção inicial, resultante do estudo exploratório sobre a produção brasileira relativa ao tema, na Brapci, foi de que as ênfases dos estudos se distribuíam entre as dimensões teórico e epistemológica (TE), tecnometodológica (TM) e sociopolítica (SP). E, com a intenção de organizar o corpus para favorecer a análise diacrônica, os artigos foram dispostos nos períodos de 1972 a 1981, 1982 a 1991, 1992 a 2001, 2002 a 2011 e 2012 a 2018.

\section{Trajetória da pesquisa}

Este estudo, de caráter analítico diacrônico e descritivo, utiliza-se de informações relativas ao perfil e produção científica dos pesquisadores da área de CI sobre o tema bibliografia, nas suas diversas acepções e vertentes. Foram levantados todos os artigos sobre o tema, dentre a produção científica registrada na Brapci, correspondente ao período entre 1972 e 2017, utilizando-se de "bibliografia" como termo de busca nos campos título, resumo e palavras-chave.

Seguindo orientação de Falkingham e Reeves (1998), para estudo de um "corpus" de publicações, foi criada uma base de dados, para facilitar o tratamento quantificável sobre o corpus. Foi então realizada uma revisão para eliminar os artigos em duplicidade e os não pertinentes, assim como eliminar artigos de revistas não publicadas no Brasil.

Foi elaborada uma lista de referências dos 280 artigos constantes do corpus, acompanhada dos resumos e palavras-chaves a eles correspondentes, a princípio em ordem cronológica de sua publicação.

Em Questão, Porto Alegre, v. 25, p. 67-88, Edição Especial V Seminário Internacional A Arte da Bibliografia, 2019 
Uma primeira leitura dos resumos e, quando necessária, dos artigos completos, permitiu a identificação de três categorias representativas das dimensões temáticas: a teórico epistemológica (TE), a tecnometodológica (TM) e a sociopolítica (SP).

Foram então discriminados em três grupos que passaram a ser analisados separadamente. A representação dessa produção foi possível graças à construção de elementos ilustrativos, além de uma linha do tempo, de 1972 a 2018, distribuída em cinco períodos, durante os quais foram destacados os acontecimentos e os produtos relacionados aos esforços pela manutenção do vínculo entre os sistemas bibliográficos e de informação e os padrões relativos às formas de produção do conhecimento.

\section{0 campo e suas dimensões}

O resultado das classificações dos trabalhos pelas suas dimensões, quando da leitura dos dados percentuais, está configurado conforme as três categorias: a Tecnometodológica, representada pela maioria do corpus, compondo um conjunto de 187 artigos (66,8\%), a Teórico e epistemológica, com 53 artigos $(18,9 \%)$ e a Sociopolítica, representada por 40 artigos $(14,3 \%)$ do corpus.

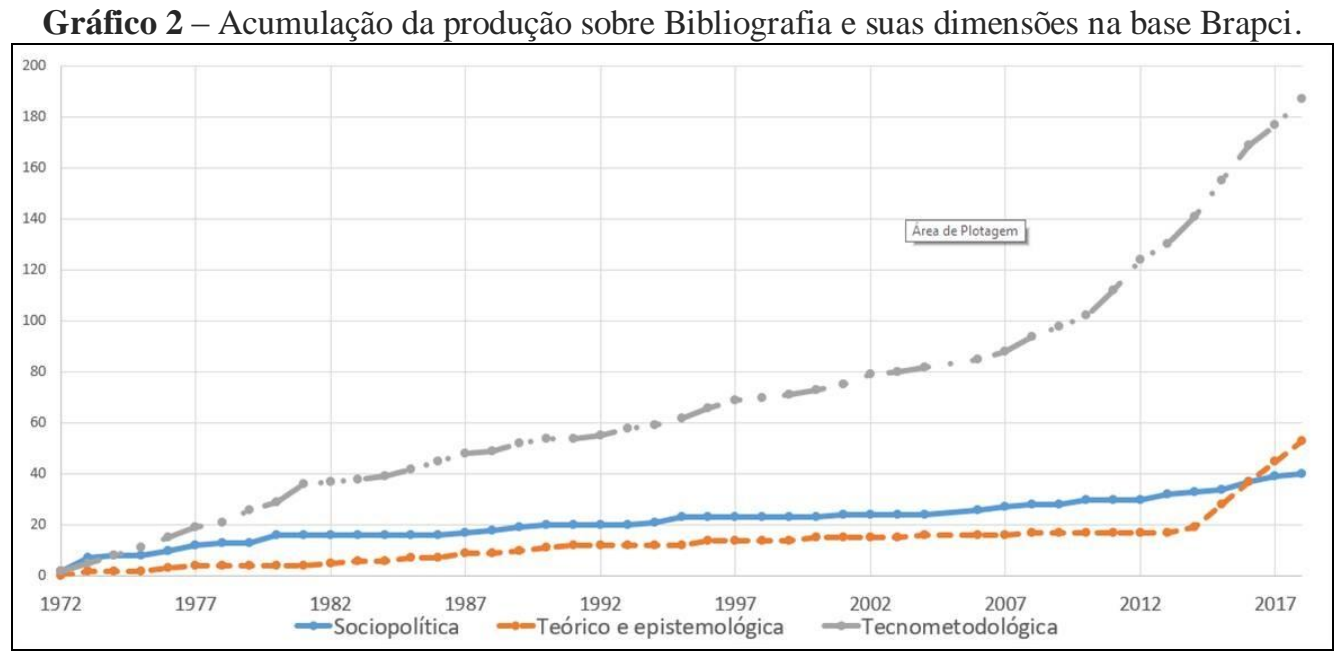

Fonte: Dados da pesquisa (2018).

O predomínio da dimensão tecnometodológica concretiza-se prioritariamente no fazer biblioteconômico, explicitando e descrevendo suas 
formas e ferramentas de trabalho e estudo. Segue-se a dimensão teórico epistemológica, relacionada aos fundamentos e reconstrução racional e histórica da arte da bibliografia e da ciência bibliográfica. A dimensão sociopolítica, por sua vez, relaciona-se concretamente às intervenções em formas variadas de apoio institucional ao conhecimento e sua concretização em prol dos interesses abrangidos pelas políticas sociais, apresentando menor expressão quantitativa no conjunto da produção.

Foi escolhida a escala +40 para a visualização dos 68 autores mais frequentes, o que permite identificar o grau de comparação entre os autores, em níveis quantitativos.

Gráfico 3-Quantidade anual de trabalhos sobre Bibliografia identificadas na base Brapci.

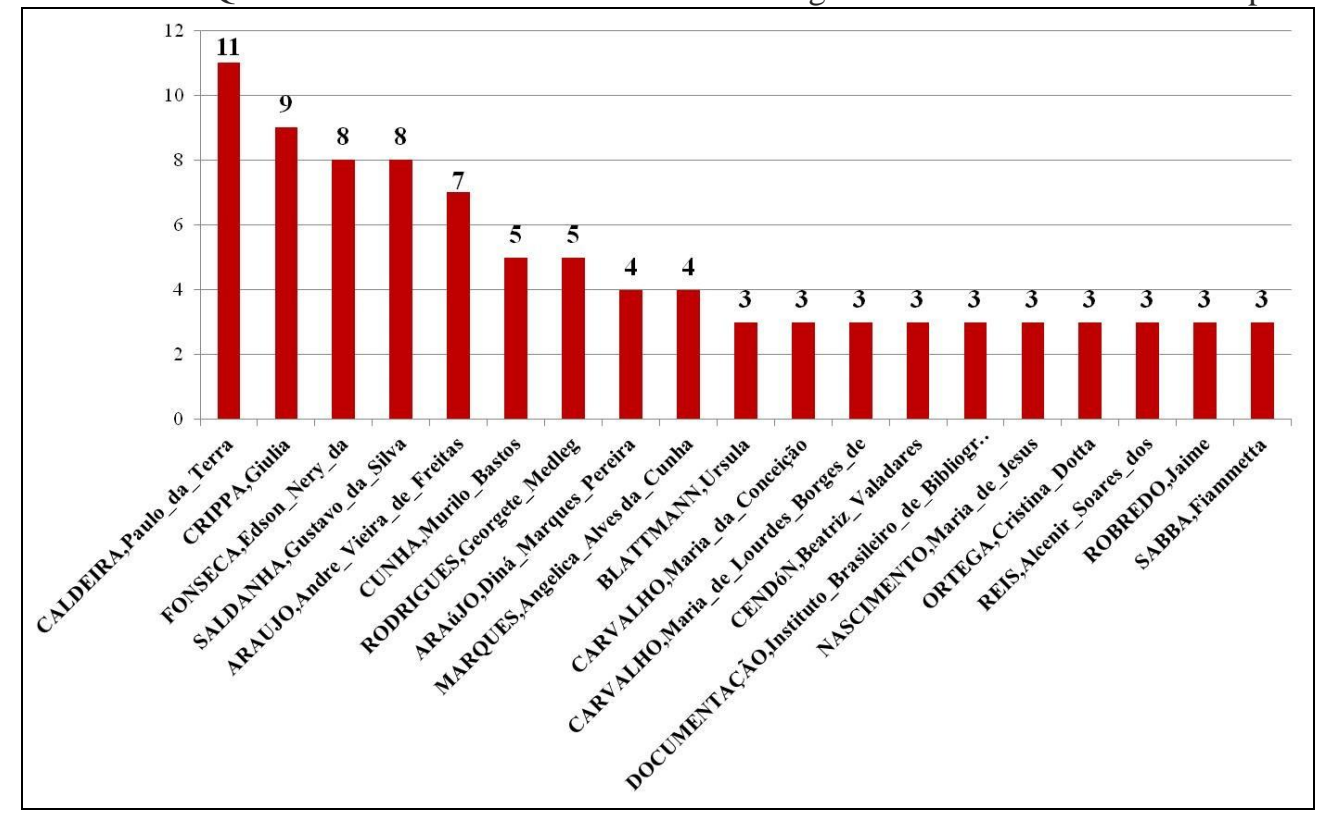

Fonte: Dados da pesquisa (2018).

Para aprofundamento desta análise, são considerados os autores com mais de cinco produções identificadas. Com posição privilegiada no ranking, Paulo da Terra Caldeira tem sua produção prioritariamente voltada à apresentação de bibliografias, ocorrendo de modo equilibrado durante os quatro primeiros períodos analisados, com trânsito prioritário na dimensão técnico metodológica. As considerações sobre estruturas, arranjos e questões de ordem prática permeiam sua produção, sempre contextualizada historicamente em relação às obras descritas e à recuperação diacrônica de elementos para Em Questão, Porto Alegre, v. 25, p. 67-88, Edição Especial V Seminário Internacional A Arte da Bibliografia, 2019 
compreensão do sentido de sua origem, além da valorização do caráter formativo da bibliografia, tanto percebida como produto elaborado para uso, quanto em relação ao seu processo de produção e ao que ele envolve enquanto aprendizagem. Em relação à trajetória intelectual do autor, destaca-se, além dessa dimensão pedagógica, o cuidado em articular elementos conjunturais por meio da análise de ocorrências que favoreceram ou não certos empreendimentos bibliográficos, tendo como base as estruturas e sua relação com a conjuntura de cada época em que ocorreram. Pode-se afirmar sua percepção sobre o conjunto de forças e problemas e como aplica suas análises procurando situar e estabelecer a lógica desses acontecimentos, assim como exercer a virtude crítica.

A produção de Giulia Crippa está principalmente relacionada à dimensão teórico epistemológica, concentrando-se no último período analisado, entre 2014 e 2018 e destaca "momentos significativos na construção e no desenvolvimento das ideias que se produziram e materializaram em formas de procedimentos bibliográficos e biblioteconômicos voltados à mediação". Percebe a Bibliografia do ponto de vista histórico-cultural, como um dos alicerces, enquanto metadisciplina, para o tratamento dos documentos. Realiza estudos e releituras historicamente contextualizados, visualiza momentos de individualização de eventos, como o tratado De Institutione Divinarum Litterarum de Cassiodoro. Volta-se ao "gesto bibliográfico" gesneriano, compreendendo-o além de uma resposta à confusa e irritante multidão de livros. Considera o perfil de autonomia alcançado pela tecnologia, principalmente no campo da informação e os problemas para o desenvolvimento da bibliografia. Volta-se à condição sócio histórica de atividades de Naudé como bibliotecário e pensador, para compreender sua produção bibliográfica, em releitura e suas obras.

Edson Nery da Fonseca destaca-se como autor histórico e seminal pelas contribuições que deu ao estudo e construção da bibliografia enquanto objeto, campo do conhecimento ou disciplina da Ciência da Informação. Está representado no corpus por oito artigos, concentrados no período de 1972 a 1980, igualmente distribuídos entre as dimensões sociopolítica e técnicometodológica. Edson Nery trata da importância das bibliografias nacionais correntes e sua evolução no Brasil, das iniciativas governamentais e particulares, 
do depósito legal e sua atualização. Caracteriza as bibliografias até então produzidas e o depósito legal e sua atualização. Sua veia crítica volta-se aos aspectos políticos, em relação às providências institucionais e as expectativas de produção e atualização das bibliografias, às considerações formais como omissões de trabalhos escritos por autores ingleses de estudos recapitulativos, eventualmente desconhecedores de línguas latinas e aos aspectos estruturais relacionados às bibliografias. Faz a recuperação histórica de acontecimentos que marcaram a cultura acadêmica, como a Biblioteca Central da Universidade de Brasília e as transformações por ela provocadas, assim como de bibliografias especializadas que contribuíram para a sociedade e de personagens como Rubens Borba de Moraes são relacionados, com menções especiais.

Gustavo Saldanha tem produção concentrada entre 2015 e 2018, na dimensão teórico epistemológica. Trata da posição da bibliografia na epistemologia de figuras históricas em seus respectivos tempos e do discurso de construção epistemológica do campo da organização dos saberes. Destacam-se as noções de Bibliografia e Bibliologias, sobre três esferas epistemológicohistóricas, fundadas nos pensamentos de Peignot, Otlet e Estivals. Analisa a possibilidade de expansão da Bibliologia, como micro ou macrosaber (macrodisciplina ou campo do conhecimento). Trata das questões da modernidade, a Gramatologia de Derrida e a Arqueologia dos Saberes de Foucault, analisando conexões subjacentes entre uma teoria do conhecimento e uma teoria bibliográfica. Argumenta que uma teoria bibliográfica do conhecimento se estabelece lentamente, constituindo uma episteme distinta em paralelo à história do próprio projeto histórico do pensamento filosófico. Seus textos tratam da uma epistemologia histórica orientada para os processos de transformação contínua do campo biblioteconômico-informacional e, em coautoria reflete sobre o sobre o lugar da bibliografia na construção da Ciência da Informação.

Andre Vieira de Freitas Araujo está representado no corpus por sete itens, concentrados entre 2015 e 2018, ocupando a dimensão teórico epistemológica o que se compatibiliza com a sua compreensão da Bibliografia como disciplina constituída por interfaces teóricas e práticas que, desde sua 
origem, têm fundamentado o tratamento documental. Retomando contribuições a essa história, ele destaca o papel de Conrad Gesner (1516-1565), visando recuperar elementos constitutivos da cultura bibliográfica e discutir o sentido da Bibliotheca Universalis, como dispositivo de mediação e memória bibliográfica. Em seus artigos volta-se ao contexto histórico-informacional da Europa Moderna e à acelerada produção de bibliografias, como meios de registro, organização, seleção, disponibilização e mediação de documentos, uma das consequências da Imprensa. Autores como Peter Burke, Ann Blair, Alfredo Serrai e Fiammetta Sabba colaboram para sua compreensão do "gesto bibliográfico" gesneriano. O autor analisa, também, a obra de Gabriel Naudé (1600-1653), por meio da bibliografia e da bibliofilia e os contextos de concepção de Advis pour dresser une bibliothèque (1627), cujos critérios e motivações culturais pautam-se em um cânon bibliográfico em consonância com a época. Também colabora para compreender a apropriação de Jesse Shera feita pelo campo da Biblioteconomia e Ciência da Informação no Brasil, entre outros aspectos de sua produção.

Com exceção de Paulo Caldeira e Edson Nery da Fonseca, os três autores de maior expressão no ranking constituem o grupo organizador do Seminário Internacional "A Arte da Bibliografia". Sua produção tem destaque nos últimos anos do espectro temporal analisado e ajusta-se à dimensão teórico epistemológica, demonstrando o papel da Bibliografia enquanto atividade e produto artístico e disciplinar, com desdobramentos marcados historicamente, sem descuidar dos aspectos metodológico e prático. O Seminário é um espaço de trocas entre pesquisadores e participantes, sinalizador da importância dos estudos bibliográficos para os fundamentos da Bibliologia, Biblioteconomia, Documentação e Ciência da Informação. O evento é uma realização do grupo de pesquisa "Ecce Liber: filosofia, linguagem e organização dos saberes" e tem sido relevante como motivador dos saberes e fazeres bibliográficos.

\subsection{Dimensão tecnometodológica}

A categoria mais presente como tema dos artigos da primeira fase representativa da produção brasileira no domínio dos estudos bibliográficos refere-se à 
dimensão técnico metodológica dos estudos. Seu tema mais representativo, analisado sob uma leitura diacrônica, volta-se à utilização de sistemas automáticos na elaboração de bibliografias científicas, cuja relevância no Brasil iniciou na década de 1970, por meio do Sistema Unidek, aplicado pela primeira vez no país a uma amostragem para a Bibliografia Brasileira de Botânica.

Destaca-se a problemática da automação de bibliografias classificadas pela Classificação Decimal Universal. O Sistema para a automação de bibliografias, descrito por Oliveira (1972), aplicado inicialmente por Malcolm Rigby na American Meteorological Society (AMS), em 1961, apresenta técnicas para a preparação de tabelas CDU com auxílio de computadores, e também para a elaboração de índices automáticos para o sistema. Exemplo desse tipo especial de índice, o Meteorological and Geoastrophysical Titles recebeu o nome de UNIDEK. A AMS produziu também índices para as novas aquisições do National Oceanographic Data Center dos Estados Unidos, do Vocabulário do Interdepartmental Committee for Atmospheric Science (ICAS), tendo sido utilizada pelo American Geological Institute (AGI) para os índices anuais do Geoscience Abstracts.

Figura 1 - Categorias da dimensão tecnometodológica.

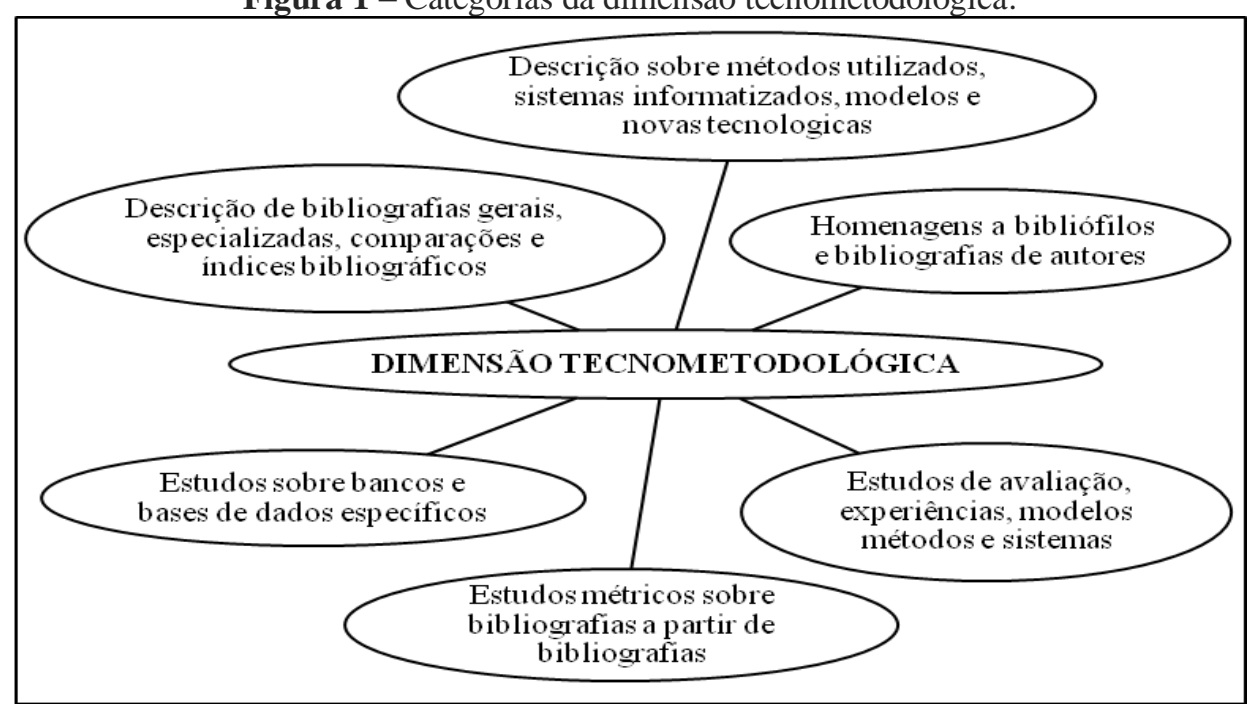

Fonte: Dados da pesquisa (2018).

A utilização de sistemas automáticos é proporcionalmente destacada desde os primeiros artigos sobre o tema, no ano de 1972, com a presença da razão tecnológica dela decorrente, principalmente por meio da automação de 
bibliografias orientadas por diferentes sistemas de classificação e ordenação. Devido ao enorme volume de dados e à necessidade de permanente atualização, os sistemas tradicionais de fichários manuais não mais satisfaziam, tornando-se impraticável a edição do Catálogo por processos normais de composição tipográfica. Estudos para a mecanização deste serviço, iniciados em 1968, foram sendo aperfeiçoados e, em 1969, sob a orientação da então Presidente do IBBD, Célia Zaher, sua automação foi concretizada pelo Convênio entre o IBBD e o Instituto de Pesquisas Espaciais (INPE) através do CNPq, para utilização do computador Burroughs 3500, instalado em São José dos Campos, SP. (DOCUMENTAÇÃO, 1973).

O período também é marcado pelas primeiras considerações sobre o aparecimento da Informática, abrangendo as ciências relacionadas com o estudo da informação (incluindo seus aspectos teóricos e aplicados), tais como especialidades desta nova ciência, ilustrados em trabalhos para responder às necessidades dos usuários com seus perfis de interesses específicos, âmbito temático no qual se incluem os estudos sobre os planos de elaboração e as metodologias de bibliografias especializadas. Ainda na década de 1970, são construídas bibliografias analíticas.

Experiências didáticos pedagógicas e de formação profissional são analisadas, assim como avaliações de experiências de controle bibliográfico e características de bibliografias utilizadas em programas de cursos.

Nesse contexto, a bibliografia especializada corrente tem papel relevante na produção analisada, assim como suas modalidades de apoio concretizadas em projetos de construção de bases de dados e automação em bibliotecas (Informática documentária). Experiências com ferramentas para construção de instrumentos bibliográficos também compõem essa dimensão, como contribuição aos pesquisadores com fontes especializadas de informações.

A intenção de homenagear personagens é ilustrada também nessa dimensão, assim como definições de tendências em obras constantes de bibliografias específicas.

Estudos de cunho metodológico, apresentando modelos ou métodos de construção e análise de bibliografias acompanham a produção de instrumentos e 
sua avaliação, como metodologias para o estabelecimento de listas básicas (core lists), relações de títulos de obras ou periódicos, em áreas específicas.

Apresentações de diretrizes para a implantação de sistemas de controle e divulgação de publicações, geração, metodologia de bases de dados e sistemas automatizados de arquivamento e busca de referências bibliográficas, em áreas específicas e aplicação de modelos de tratamento técnico para organização de conjuntos documentais compõem um conjunto de experimentos historicamente representativos de um processo de consolidação de metodologias e modelos para a produção, difusão e uso de fontes bibliográficas no Brasil.

Estudos bibliométricos também acompanham essa dimensão, com motivações diversas e setorializadas, sobre a distribuição de literaturas específicas, com foco em bibliografias gerais e especializadas.

Estudos críticos voltam-se às realizações bibliográficas, dirigindo-se a aspectos indicadores da precariedade dos serviços na sua origem e demonstram as preocupações com a sua evolução e aperfeiçoamento. Desde as dificuldades de identificar, selecionar e localizar o material bibliográfico sobre determinadas áreas, passando pela falta de obras de referência brasileiras em áreas específicas, pela irregularidade na publicação da Bibliografia Brasileira e das bibliografias brasileiras especializadas, assim como pela necessidade de compilar ou completar as lacunas existentes na cobertura da bibliografia brasileira retrospectiva, tornando-a instrumento efetivo para a pesquisa, críticas constantes são dirigidas à bibliografia brasileira corrente, que, além de ter sofrido várias interrupções no decorrer de sua história, caracterizava-se pela incompletude.

\subsection{Dimensão teórico epistemológica}

Entre os aspectos teóricos e epistemológicos da bibliografia como objeto de estudo, destacam-se os acontecimentos históricos, como a invenção da imprensa, especialmente no esforço de divulgar o conhecimento acumulado nos livros, por meio dos repertórios dos livreiros e a publicidade de seus estoques, transformados, em alguns casos, em bibliografias nacionais. Complementarmente, surgiram as bibliografias especializadas, inicialmente de caráter internacional, como reflexo da erudição de seus autores (ZAHER; 
GOMES, 1972). Assim é reconhecida a bibliografia, no artigo inaugural do tema, por Zaher e Gomes, ao destacarem sua imprescindível presença como instrumento para a pesquisa e o desenvolvimento científico-tecnológico, objeto de preocupação de estudiosos com vistas ao aprimoramento de métodos e técnicas de divulgação do material bibliográfico existente.

Figura 2 - Categorias da dimensão teórico epistemológica.

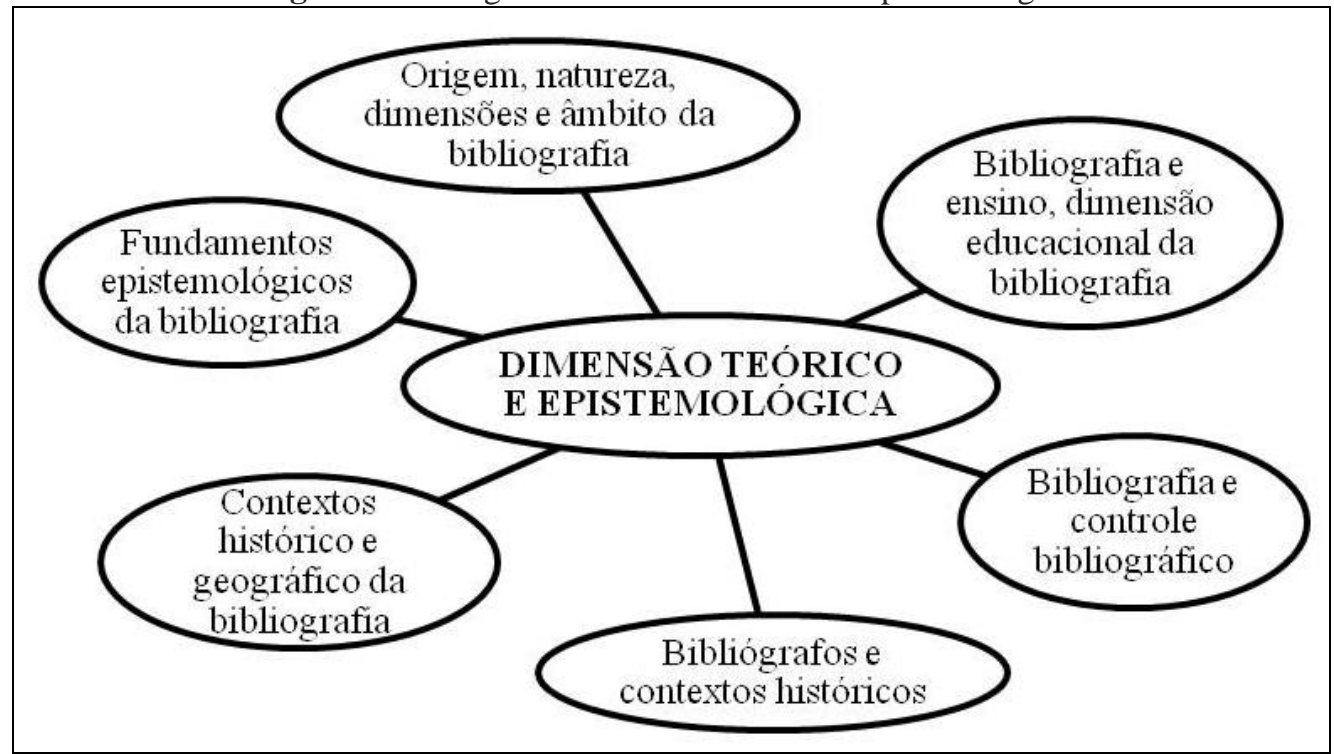

Fonte: Dados da pesquisa (2018).

Mas a intenção de criar uma bibliografia universal perpassou séculos e, ao idealizarem a criação do Office International de Bibliographie, cujo trabalho originou o Instituto Internacional de Bibliografia, após o $1^{\circ}$ Congresso Internacional de Bibliografia, em 1895, Paul Otlet e Henri La Fontaine, previram a criação da biblioteca universal, com regras comuns para o tratamento analítico sintético dos documentos, como solução para o problema de acesso ao conteúdo. O principal ponto positivo, nesta primeira fase, até hoje considerado fator primordial de sucesso nos programas de caráter-internacional, é o da normalização. De fato, o desenvolvimento de um sistema de classificação único, a ser adotado e compreendido por todos, nada mais era que a criação de um padrão.

Assim, novas formas de registro de informações ampliaram o âmbito da Bibliografia e, segundo Zaher e Gomes (1972), levaram ao aparecimento da Documentação, atendendo às necessidades sociais que exigiam maior 
especificidade no tratamento de informação. Com essa orientação, novos tipos de especialistas e tecnologias afloraram, originando a Ciência da Informação.

Essa dimensão abrange questões relacionadas: à origem, natureza e âmbito da bibliografia; aos fundamentos teóricos da bibliografia; aos seus contextos histórico e geográfico; aos bibliógrafos e seus contextos históricos; à bibliografia em relação ao controle bibliográfico e à bibliografia e sua dimensão educacional.

\subsection{Dimensão sociopolítica}

A dimensão sociopolítica já se configura concretamente na primeira década representativa da produção analisada, quando, nas Recomendações do IV Congresso Brasileiro de Bibliografia e Documentação (1972), publicadas na Revista da Escola de Biblioteconomia da UFMG, recomenda-se a constituição de um grupo de trabalho permanente subordinado à Federação Brasileira de Associações de Bibliotecários, Cientistas da Informação e Instituições (FEBAB), com o encargo de preparar e distribuir a bibliografia atualizada de Biblioteconomia e Documentação, competindo às associações o fornecimento de informações para a elaboração dessa bibliografia.

No mesmo ano, LaVahn Marie Overmyer (1972), professora associada da Case Western Reserve University, de Ohio ao considerar que a biblioteca amplia seu papel social para atingir usuários de todas as idades, todos os níveis econômicos e todos os meios sociais, observa que as pesquisas passam a se orientar ao papel das bibliotecas nos sistemas nacionais de informação. Desde a década de 1960, as bibliotecas americanas, dispondo de acesso ao computador, passam a desenvolver sistemas integrados e redes de informação, dos quais um dos mais modernos e bem sucedidos viria a ser o Ohio College Library Center (OCLC) nos Estados Unidos, que incorpora o uso das fitas magnéticas do Projeto MARC. No Brasil, o primeiro curso de Pós-Graduação em nível de Mestrado foi iniciado em 1970 no Instituto Brasileiro de Bibliografia e Documentação, em convênio com a Universidade Federal do Rio de Janeiro. Vários aspectos deste Curso, do qual participou a autora entre outros professores 
estrangeiros, indicam inovações e planejamento com vistas ao futuro da Biblioteconomia Brasileira e de seu papel para a sociedade.

A dimensão sociopolítica inclui, assim, cinco categorias: a institucionalização da bibliografia e dos estudos bibliográficos; as políticas, planos e programas relacionados à bibliografia; a Bibliografia nacional, o Boletim Bibliográfico e o Depósito Legal (estabelecido no Brasil pelo Decreto Legislativo $n^{\circ} 433$, de 3 de julho de 1847); os serviços de cooperação e o Catálogo nacional de Periódicos e a Infraestrutura de Informação, Ciência e Tecnologia.

Figura 3 - Categorias da dimensão sociopolítica

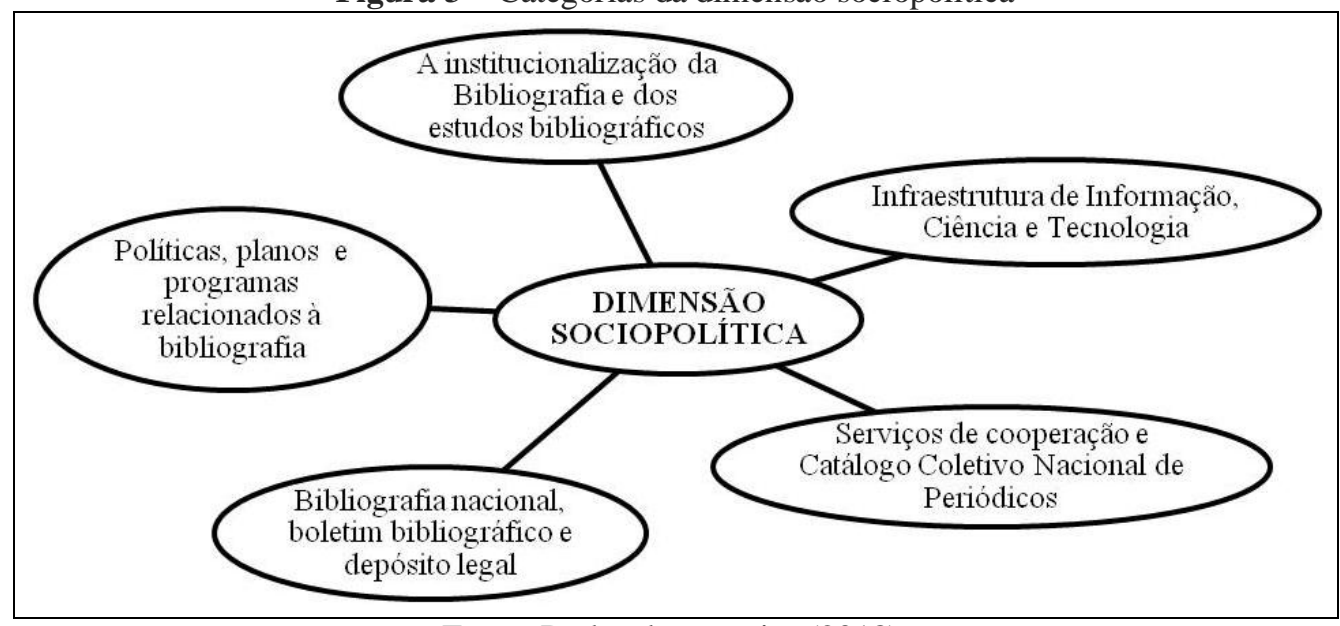

Fonte: Dados da pesquisa (2018).

Nessa dimensão observa-se a ênfase recebida pela Bibliografia Nacional Brasileira, seu histórico e inflexões, graças ao seu papel de destaque como instrumento de pesquisa e memória da produção intelectual da sociedade. Sua construção, trajetória histórica é perceptível como objeto de estudo. Em diferentes épocas e contextos, sobretudo em publicações de Edson Nery da Fonseca podem-se elucidar papéis políticos de diferentes instituições ao longo da história como responsáveis pela construção e institucionalização desse e de outros instrumentos. 


\section{Considerações finais}

Como síntese do panorama analisado, destaca-se uma dimensão cultural e humanística presente na literatura sobre o percurso das bibliografias no Brasil, na expectativa de valorizar esse tipo de produção para a organização, construção e recuperação do conhecimento, tanto em suas dimensões locais, quanto internacionais. É possível também acompanhar uma linha de pensamento manifesta concretamente na produção científica sobre o tema, expressa em periódicos nacionais.

Destaca-se a dimensão técnica metodológica, o que se explica pelo fato de que, desde a década de 1970, devido aos avanços cumulativos advindos da tecnologia, ampliam-se as possibilidades trazidas pelo desenvolvimento de metodologias de produção de bibliografias e organização de sistemas operacionais apropriados e sempre atuantes.

Essa evidência, entretanto, não prescinde da dimensão teórico epistemológica, cuja ênfase tem sido dirigida à íntima relação entre conteúdos e formas de realização do conhecimento e cuja tendência de crescimento ascendente, na última década de produção, é especialmente privilegiada por um dos grupos de pesquisa sobre o tema, significativamente representado no corpus da produção científica aqui analisada, como nova geração, coesa e ativa na produção científica e na realização de eventos.

\section{Agradecimentos}

Ao CNPq, na condição da autora como bolsista PQ1D.

Ao professor doutor Rene Faustino Gabriel Junior e ao professor mestre Márcio Henrique Wanderley Ferreira pelas contribuições ao artigo.

\section{Referências}

ALVARES JUNIOR, L. S.; SALDANHA, G. S. A bibliografia como ciência. Perspectivas em Ciência da Informação, Belo Horizonte, v. 22, número especial, p. 199-202, 2017. Disponível em: <http://portaldeperiodicos.eci.ufmg.br/index.php/pci/article/view/3241/1919>. Acesso em: 27 abr. 2019. 
ARAUJO, A. V. F.; Pioneirismo bibliográfico em um polímeta do séc. XVI: Conrad Gesner. Informação \& Informação, Londrina, v. 20, n. 2, p. 118-142, 2015. Disponível em: <http://www.brapci.inf.br/index.php/res/v/31569>.

Acesso em: 29 abr. 2019.

ARAUJO, A. V. F.; CRIPPA, G.; SALDANHA, G. S.; Em busca da Bibliografia: sobre o I Seminário Internacional "A Arte da Bibliografia". Revista Brasileira de Biblioteconomia e Documentação, n. Especial, v. 11, p. 495-512, 2015. Disponível em: http://www.brapci.inf.br/index.php/res/v/1574. Acesso em: 29 abr. 2019.

BORGES, Jorge Luís. Cinco visões pessoais. Brasília: Ed. Universidade de Brasília, 1985. p. 136-153. (Coleção Itinerárias, 17).

BRIET, Susanne. Qu'es-ce que la documentation? Paris: Éditions Documentaires Industrieles et Techiques, 1951.

BUCKLAND, Michael. Paul Otlet. Disponível em: $<$ http://people.ischool.berkeley.edu/ buckland/otlet.html>. Acesso em: 26 nov. 2018.

BUFREM, L. S.; COSTA, F. D. O.; GABRIEL JUNIOR, R. F.; PINTO, J. S. P. Modelizando práticas para a socialização de informações: a construção de saberes no ensino superior. Perspectivas em Ciência da Informação, Belo Horizonte, v. 15, n. 2, p. 22-41, 2010. Disponível em: < http://portaldeperiodicos.eci.ufmg.br/index.php/pci/article/view/1069/730>. Acesso em: 27 abr. 2019.

CALDEIRA, P. da T.; CARVALHO, M. de L. B. de; Bibliografia retrospectiva: um instrumento para a análise do desenvolvimento científico e cultural do Brasil. Revista da Escola de Biblioteconomia da UFMG, Belo Horizonte, n. 1, v. 9, p. 50-68, 1980. Disponível em:

http://www.brapci.inf.br/index.php/res/v/75923. Acesso em: 25 abr. 2019.

CALDEIRA, P. da T. Bibliógrafos brasileiros: levantamento preliminar. Revista Brasileira de Biblioteconomia e Documentação, v. 16, n. 1/2, p. 37-44, jan/jun, 1983.

CALDEIRA, P. da T.; CARVALHO, M. L. B. de; A importância dos recursos bibliográficos brasileiros para os usuários da informação científica. Cadernos de Biblioteconomia, n. 1, v. 6, p. 137-144, 1983.

CHALHUB, Tania. Ações para implantação de repositórios institucionais em universidades públicas no Estado do Rio de Janeiro. Informação \& Sociedade: Estudos, João Pessoa, v. 22, n. 2, p. 115-126, maio/ago. 2012. Disponível em: <http://www.periodicos.ufpb.br/ojs/index.php/ies/article/view/12147/7761>. Acesso em: 27 abr. 2019.

Em Questão, Porto Alegre, v. 25, p. 67-88, Edição Especial V Seminário Internacional A Arte da Bibliografia, 2019 doi: http://dx.doi.org/10.19132/1808-5245250.67-88 
DRUMOND, G. M.; MEXAS, M. P.; BEZERRA, M. J. S. A aquisição de livros em bibliotecas universitárias sob a perspectiva da gestão de processos. Revista Brasileira de Biblioteconomia e Documentação, São Paulo, v. 14, n. 2, 2018. Disponível em: <https://rbbd.febab.org.br/rbbd/article/view/698/1047>. Acesso em: 27 abr. 2019.

DUVIGNAUD, Jean. Prefácio. In: HALBWACHS, Maurice. A memória coletiva. São Paulo: Vértice, 1990. p. 9-17. (Biblioteca Vértice. Sociologia e Política).

FALKINGHAM, L. T.; REEVES, R. Context analysis: a technique for analyzing research in a field, applied to literature on the management of R\&D at the section level. Scientometrics, Amsterdam, v. 42, n. 2, p. 97-120, 1998.

FONSECA, E. N. da. América Latina e Caribe: uma bibliografia dissertação. Revista de Biblioteconomia de Brasília, Brasília, v. 7, n. 1, p. 123-129, 1979. Disponível em: <http://www.brapci.inf.br/index.php/res/v/78224>. Acesso em: 29 abr. 2019.

FONSECA, E. N. da. Bibliografia Brasileira Corrente: Evolução e Estado Atual do Problema. Ciência da Informação, Brasília, v. 1, n. 1, p. 9-14, 1972. Disponível em: http://www.brapci.inf.br/index.php/res/v/21082. Acesso em: 24 abr. 2018.

FONSECA, E. N. da. Bibliografia Estatística e Bibliometria: uma Reivindicação de Prioridades. Distribuição da Literatura Geológica Brasileira: Estudo Bibliométrico. Ciência da Informação, Brasília, v. 2, n. 1, p. 5-7, 1973. Disponível em: http://www.brapci.inf.br/index.php/res/v/19702 Acesso em: 24 abr. 2018.

FONSECA, E. N. da. Bibliografia Folclórica. Revista de Biblioteconomia de Brasília, Brasília, v. 7, n. 1, p. 123-129, 1979. Disponível em: http://www.brapci.inf.br/index.php/res/v/78225 Acesso em: 24 abr. 2018.

FONSECA, E. N. da. Rubens Borba de Moraes e a Bibliografia Brasileira. Revista de Biblioteconomia de Brasília, n. 1, v. 7, p. 5-8, 1979. Disponível em: http://www.brapci.inf.br/index.php/res/v/75502 Acesso em: 24 abr. 2018.

LIMA, F. R. B.; SANTOS, P. L. V. A. C. A ubiquidade das artes nos ambientes virtuais de contemplação: imergindo na pinacoteca do estado de São Paulo. Em Questão, Porto Alegre, v. 24, n. 1, p. 174-193. Disponível em: <https://seer.ufrgs.br/EmQuestao/article/view/71125/44462>. Acesso em: 27 abr. 2019.

LIMA, M. H. T. F.; VICENTE, L. P. Bibliotecas públicas do Rio Grande do Sul e o patrimônio edificado: valor, no fundo, simbólico. Revista P2P e

Em Questão, Porto Alegre, v. 25, p. 67-88, Edição Especial V Seminário Internacional A Arte da Bibliografia, 2019 doi: http://dx.doi.org/10.19132/1808-5245250.67-88 
INOVAÇÃO, Rio de Janeiro, v. 4, n. 2, p. 70-94. Disponível em: <http://revista.ibict.br/p2p/article/view/4204/3608>. Acesso em: 27 abr. 2019.

MOURAVIT, Gustave. Le Livre et la petite bibliothèque d'amateur, essai de critique, d'histoire et de philosophie morale sur l'Amour des Livres. Paris: Auguste Aubry, 1869. In-8, (4 ff.), Xxii pp., (1 f.), 447 p. Disponível em: https://gallica.bnf.fr/ark:/12148/bpt6k165065z.image. Acesso em: 27 abr. 2019.

SHERA, J. H. Toward a theory of Librarianship and information Science. Ciência da Informação, Brasília, v. 2, n. 2, p. 87-97, 1972. Disponível em: <http://revista.ibict.br/ciinf/article/view/30/30>. Acesso em: 27 abr. 2019.

\title{
The Brazilian scientific production on bibliographic studies: a diachronic analysis
}

\begin{abstract}
It describes the theoretical conceptions and concrete activities related to the field of Bibliography in Brazil, considering its theoretical and applied development, from scientific production in journal articles indexed in Brapci. The research aims at identifying the production about the subject of bibliography by searching the analysis of scientific literature indexed in Brapci; outlining the profile of this production, favoring the categories of researchers, themes and theoretical influences from the Information Science field and contextualizing the conceptions and activities in the scenario in which it was highlighted. The research diachronically analyzes the production on the subject, to highlight the evolution of the concept of bibliography in scientific production in Brazil, highlighting the relevant concepts and activities. It is a study of diachronic and descriptive character, which turns to the content of the articles, based on categories of analysis and information raised in the considered scientific production, corresponding to the period between 1972 and 2017. It also observes that in the literature produced in Brazil on the subject of bibliography, the emphasis is on the techno-methodological dimension, implemented in Librarian Science and documentary, explaining and organizing work and study tools, following the socio-political dimension related to the interventions in various forms in the production of instruments to support knowledge and its achievements in favor of the interests covered by social policies and, less expressively, in the whole of production, presents the epistemological theoretical dimension, related to the foundations and rational and historical reconstruction of the art of bibliography and bibliographic science.
\end{abstract}

Keywords: Bibliography. Scientific Production. Bibliography in Brazil. Bibliographic Study. 


\begin{abstract}
${ }^{1}$ A partir da decisão institucional binacional, com a participação dos professores Elías Sanz Casado e José Antonio Moreiro González, da Universidad Carlos III de Madrid (UC3M), e da Professora Doutora Wanda Maria Maia da Rocha Paranhos, foi concebida, então a Base Brasil/Espanha de Artigos de Periódicos da área em Ciência da Informação (Bres), coordenada pela professora Bufrem, objeto de estudo e fonte de pesquisas dos grupos de pesquisa coordenados pelos professores Elías Sanz Casado, da UC3M e da pesquisadora Bufrem, da UFPR.

Hoje, a Brapci é coordenada pelo professor doutor Rene Faustino Gabriel Junior (UFRGS) $<$ renefgj@gmail.com>
\end{abstract}

